Abstracta Iranica Iranica

Revue bibliographique pour le domaine irano-aryen

Volume 25 | 2004

Comptes rendus des publications de 2002

\title{
Sujab Ak Bešim. Saint-Petersbourg, Musée de l'Ermitage, 2002, 174 p.
}

\section{Étienne de La Vaissière}

\section{(2) OpenEdition}

1 Journals

\section{Édition électronique}

URL : http://journals.openedition.org/abstractairanica/4238

DOI : $10.4000 /$ abstractairanica.4238

ISSN : 1961-960X

Éditeur :

CNRS (UMR 7528 Mondes iraniens et indiens), Éditions de l'IFRI

\section{Édition imprimée}

Date de publication : 15 mai 2004

ISSN : 0240-8910

\section{Référence électronique}

Étienne de La Vaissière, «Sujab Ak Bešim. Saint-Petersbourg, Musée de l'Ermitage, 2002, 174 p. », Abstracta Iranica [En ligne], Volume 25 | 2004, document 60, mis en ligne le 15 mars 2006, consulté le 25 septembre 2020. URL : http://journals.openedition.org/abstractairanica/4238 ; DOI : https:// doi.org/10.4000/abstractairanica.4238

Ce document a été généré automatiquement le 25 septembre 2020.

Tous droits réservés 


\title{
Sujab Ak Bešim. Saint-Petersbourg, Musée de l'Ermitage, 2002, 174 p.
}

\author{
Étienne de La Vaissière
}

1 Ce recueil forme la plus récente synthèse sur l'histoire du site sogdo-turc de Suyab, fondé au $5^{\mathrm{e}}$ ou au $6^{\mathrm{e}} \mathrm{s}$., épisodiquement point d'appui des garnisons chinoises aux $7^{\mathrm{e}}$ et $8^{\text {e }}$ siècles (Suye) plus tard et qui est remplacé comme principal centre urbain du Semirech'e par la capitale qarakhanide Balasaghun, à quelques kilomètres au sud, à la fin $\mathrm{du} 10^{\mathrm{e}} \mathrm{s}$. L'institut d'histoire kirghize et le musée de l'Ermitage y ont organisé des fouilles entre 1996 et 1998, qui ne se sont malheureusement pas poursuivies. Le bilan est impressionnant, tant pour l'histoire du Semirech'e, que pour celle du nestorianisme ou de la présence chinoise : un complexe ecclésial a en effet été dégagé dans la ville, des inscriptions chinoises et sogdiennes retrouvées, la chronologie de la citadelle précisée. L'ouvrage, illustré de nombreuses photos, plans dessins et tables, comprend :

2 - un bref rappel de l'histoire des fouilles (G. Semenov, pp. 4-10), rappelant notamment les fouilles de Bernštam et de Kyzlasov (notamment sur les temples bouddhistes et l'église hors les murs) ;

3 - le rapport sur les fouilles de deux des trois zones fouillées, la citadelle et le complexe ecclésial (la fouille du sharistan manque) par G. Semenov, pp. 11-114 :

4 À la citadelle ont été découverts deux éléments intéressants : en terme de chronologie, il semble que la citadelle s'appuie sur le premier mur de la ville, qui par son architecture (forme des tours) ne semble pas être antérieur au $6^{\mathrm{e}} \mathrm{s}$., ce qui permet de circonscrire la période de fondation (habituellement $5^{\mathrm{e}} 6^{\mathrm{e}} \mathrm{s}$.), mais aussi de mettre à bas le schéma classique, celui de la fondation autour d'un Kušk nobiliaire : le mur de la ville est premier. D'autre part a été dégagée une cour entourée de quatre iwans dans la dernière occupation de la zone, du $10^{\mathrm{e}}-11^{\mathrm{e}} \mathrm{s}$.

5 La découverte d'un second ensemble ecclésial du $10^{\mathrm{e}} \mathrm{s}$., après l'église hors les murs (du $8^{\mathrm{e}} \mathrm{s}$.), est très intéressante en particulier en raison du plan de ce complexe, très proche de celui de Ain Shai'a en Iraq ou de Geras en Jordanie. Des peintures très fragmentaires, des inscriptions et les restes d'un codex ont également été découverts, pour ces derniers malheureusement illisibles. Le caractère massif de l'ensemble (environ 60 sur 
$46 \mathrm{~m}$.), la place qu'il occupe dans la ville haute, dans l'angle sud-est symétrique de l'angle sud-ouest occupé par la citadelle, soulignent l'importance et le prestige dont devait jouir le nestorianisme dans la ville. Plusieurs croix nestoriennes y ont été retrouvées, certaines inscrites. Un pressoir à vin faisait partie du complexe.

6 - les inscriptions chinoises par E. Lubo-Lesničenko $(\dagger)$ pp. 115-127 en fait un inventaire complet des mentions de la ville dans les sources chinoises (documents de Turfan inclus) et une publication des deux inscriptions chinoises trouvées sur le site ;

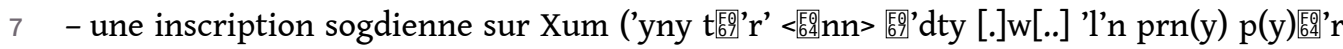

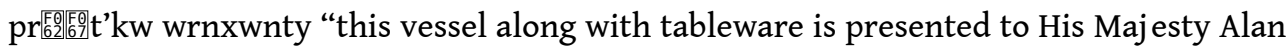
the prosperous"), avec une comparaison avec des inscriptions similaires de Krasnaja Rečka, par V. Livšic, pp. 128-133 ;

8 - des inscriptions turques trouvées dans une vallée au sud-est éditées par S. Kljaštornij, pp. 134-141: une version anglaise de ce texte est publiée dans le numéro 8 de SRAA (voir c.r. $\mathrm{n}^{\circ} 58$ ) ;

9 - les éléments d'armure et pointes de flèche trouvés sur le site du complexe ecclésial (A. Bexter, pp. 142-156) ;

10 - les trouvailles monétaires turgeš, tuHssı, chinoises... (A. Kamyšev, pp. 157-166);

11 - les inscriptions sur les monnaies (V. Livšic, pp. 167-169);

12 - conclusion et résumé anglais.

\section{INDEX}

Thèmes : 3.1. Est de l'Iran

\section{AUTEURS}

ÉTIENNE DE LA VAISSIÈRE

EPHE - ENS - Paris 